\title{
Large-scale industrial cloud perturbations confirm bidirectional cloud water responses to anthropogenic aerosols
}

Article

Accepted Version

Trofimov, H., Bellouin, N. and Toll, V. (2020) Large-scale industrial cloud perturbations confirm bidirectional cloud water responses to anthropogenic aerosols. Journal of Geophysical Research: Atmospheres, 125 (14). e2020JD032575. ISSN 2169-8996 doi: https://doi.org/10.1029/2020JD032575 Available at https://centaur.reading.ac.uk/91920/

It is advisable to refer to the publisher's version if you intend to cite from the work. See Guidance on citing.

To link to this article DOI: http://dx.doi.org/10.1029/2020JD032575

Publisher: American Geophysical Union

All outputs in CentAUR are protected by Intellectual Property Rights law, including copyright law. Copyright and IPR is retained by the creators or other copyright holders. Terms and conditions for use of this material are defined in the End User Agreement.

www.reading.ac.uk/centaur 
Central Archive at the University of Reading

Reading's research outputs online 
$5 \quad$ Heido Trofimov ${ }^{1}$, Nicolas Bellouin ${ }^{2}$, Velle Toll ${ }^{1}$

$6 \quad{ }^{1}$ Laboratory of Atmospheric Physics, University of Tartu, Tartu, Estonia

$7 \quad{ }^{2}$ Department of Meteorology, University of Reading, Reading, UK

8

9 Corresponding authors: Heido Trofimov (heidot@ut.ee), Velle Toll (velle.toll@ut.ee)

\section{Key Points:}

- Satellite observations confirm aerosol-induced decreases in cloud droplet size in large areas compared to nearby less polluted areas

- Aerosol-induced cloud water increases and decreases compensate each other at large spatial scales similarly to ship-track-like perturbations

- On average, Twomey effect is more important than the effect of cloud water changes for the aerosol radiative forcing of the Earth's climate 


\section{Abstract}

Aerosols offset a poorly quantified fraction of anthropogenic greenhouse gas warming, and the aerosol impact on clouds is the most uncertain mechanism of anthropogenic climate forcing. Here, observations of a relatively weak average response of liquid cloud water to aerosol perturbations are extended to much larger areas than in previous studies, with the polluted cloud areas covering hundreds by hundreds of kilometers. Polluted clouds detected in satellite images at the global anthropogenic air pollution hot spot of Norilsk, Russia, and at other various major aerosol source regions show close compensation between aerosol-induced cloud water increases and decreases. In the sampled Norilsk cloud perturbations the decrease in LWP offsets $3 \%$ of the radiative forcing through the Twomey effect on average. Weak cloud water response on average in large polluted areas is in very good agreement with previous results based on observations of small-scale ship-track-like industrial cloud perturbations, helping to reduce the uncertainty associated with the anthropogenic aerosol impacts on clouds.

\section{Plain Language Summary}

It is unknown to what extent the global cooling effect of anthropogenic aerosols offsets the warming effect of anthropogenic greenhouse gases. The strength of the aerosol climate cooling effect exerted through changes in the properties of clouds is especially uncertain. This hinders better estimates of Earth's climate sensitivity to anthropogenic radiative forcing and more reliable projections of future climate. It has been previously found that the average aerosolinduced cloud water change is relatively weak in smaller-scale ship-track-like polluted cloud tracks. Here we analyze satellite observations of much larger-scale polluted cloud areas, with the polluted cloud areas covering hundreds by hundreds of kilometers. Polluted clouds over Norilsk, Russia, and over other various major aerosol source regions show close compensation between aerosol-induced cloud water increases and decreases. Large scale polluted cloud areas indicate that the effect that aerosols have on cloud droplet sizes has a stronger impact on Earth's climate than the effect caused by the cloud water changes. These results help to reduce the uncertainty associated with the anthropogenic aerosol impacts on clouds and Earth's climate.

0305 Aerosols and particles

1640 Remote sensing 
3311 Clouds and aerosols Aerosol-cloud interaction Aerosol radiative forcing Cloud water response

\section{Introduction}

Aerosols, through directly scattering and absorbing radiation and through acting as cloud condensation nuclei, have a cooling effect on the Earth's climate. The weakly constrained influence of aerosols on Earth's climate dominates the uncertainty in anthropogenic impacts on climate (Boucher 2013). Moreover, the limited knowledge of the radiative forcing induced by aerosols since preindustrial time hinders better estimates of climate sensitivity to radiative forcing from the observational record (Stevens et al., 2016; Bellouin et al., 2019).

Radiative forcing of climate through aerosol-cloud interactions is much more uncertain than aerosol-radiation interactions (Bellouin et al., 2019). Aerosols increase cloud droplet number concentration (CDNC) and decrease the size of cloud droplets and thereby raise the cloud albedo, an effect called the Twomey effect (Twomey et al., 1974). Increased CDNCs lead to cloud adjustments resulting in changes in the cloud water content and horizontal extent of clouds. The radiative forcing through cloud adjustments is especially uncertain (Bellouin et al., 2019). Here we focus on aerosol-induced changes in cloud water content.

It was previously postulated that aerosols unidirectionally increase cloud water content through reduced precipitation due to decreased collision-coalescence efficiency of smaller cloud droplets (Albrecht 1989). The assumption of unidirectionally increased liquid water path (LWP) caused by reduced precipitation is still used in general circulation models (GCMs) today (Quaas et al., 2009; Ghan et al., 2016; Mulcahy et al., 2018; Gettelman et al.,2019). However, this assumption has been strongly challenged by recent observational studies (e.g. Toll et al., 2019; Malavelle et al., 2017). Aerosol perturbations can enhance the evaporation of cloud water and enhance entrainment of dry air that results in reduced LWP (Ackerman et al., 2004; Bretherton et al., 2007, Small et al., 2009; Hill \& Feingold 2009).

Recent lines of evidence for average LWP response to anthropogenic aerosols are still conflicting (Toll et al., 2019; Gryspeerdt et al., 2019; McCoy et al., 2019; Rosenfeld et al., 2019; 
Malavelle et al., 2017). Analysis of relationships between CDNC and LWP indicate a considerable increase (McCoy et al., 2019) or decrease (Gryspeerdt et al., 2019) in LWP on average, depending on the analysis method. McCoy et al. (2019) estimated that the increase in LWP causes radiative forcing $-1 \mathrm{~W} / \mathrm{m}^{2}$. In strong contrast with this, Gryspeerdt et al. (2019) estimated that decrease in LWP off-sets $62 \%$ of the radiative forcing by the Twomey effect.

The most direct approach to study aerosol-cloud interactions is to study temporal or spatial anomalies in cloud properties that are directly induced by aerosols (Toll et al., 2019). Malavelle et al. (2017) found no significant change in LWP in the case of the eruption of the 2014 Holuhraun volcano compared to the years preceding the eruption. Toll et al. (2019) compared the properties of the ship-track-like polluted cloud tracks to the properties of the nearby unpolluted clouds. These ship-track-like polluted cloud tracks are quasi-linear polluted cloud lines, where cloud droplet size is decreased compared to the nearby unpolluted clouds. Toll et al. (2019) found good agreement between LWP changes in the ocean-based volcano and ship tracks and land-based industry and fire tracks. Toll et al. (2019) estimated that on average, the decrease in LWP offsets $29 \%$ of the radiative forcing by the Twomey effect, which is a relatively weak offset compared to the estimates by McCoy et al. (2019) and Gryspeerdt et al. (2019).

A challenge to the representativity of cloud responses obtained by studies based on small-scale pollution tracks is that mesoscale circulation could modulate the LWP response in pollution tracks (Mülmenstädt \& Feingold, 2018; Possner et al., 2018) The width of polluted cloud tracks studied by Toll et al. (2019) was limited to tens of kilometers and they sampled only a limited number of larger-scale cloud perturbations in regions of Moscow, Russia and Kazakhstan. Here we extend their analysis of polluted cloud tracks and analyze LWP responses to aerosols in Norilsk, Russia and a variety of other regions with large-scale aerosol-induced gradients in cloud droplet size. All the analyzed data is unique to this study. The polluted cloud areas studied here cover hundreds by hundreds of kilometers. We evaluate the level of agreement between LWP responses in small-scale pollution tracks and large-scale aerosol-induced cloud perturbations.

\section{Methods}

We analyze the LWP responses to aerosols by directly comparing the properties of polluted clouds to those of the nearby unpolluted clouds following Toll et al. (2019) while focusing on 
large-scale aerosol perturbations on clouds (Fig. 1 and 2). First, we visually detect large-scale polluted areas on composite Terra Moderate Resolution Imaging Spectroradiometer (MODIS) satellite images from National Aeronautics and Space Administration (NASA) Global Imagery Browse Services (GIBS). In these composite images, MODIS bands corresponding to wavelengths $0.459-0.479 \mu \mathrm{m}, 1.628-1.652 \mu \mathrm{m}$ and $2.105-2.155 \mu \mathrm{m}$ are used. Polluted clouds stand out due to their enhanced near-infrared reflectance (Fig. 1 and 2).

After polluted clouds were identified in the images from NASA GIBS, polluted areas were logged, using $2.1 \mu \mathrm{m}$ band reflectance from Terra and Aqua MODIS retrievals. We identified polluted clouds visually as areas with enhanced reflectance on the $2.1 \mu \mathrm{m}$ band images. Enhanced $2.1 \mu \mathrm{m}$ reflectance results from aerosol-induced decreases in cloud droplet radii (Coakley et al., 1987). In each case, the polluted cloud was sampled at least from 4 different directions; if possible, from the intercardinal directions. For each direction, we manually drew a line along a horizontal gradient in near-infrared reflectance (from unpolluted clouds into polluted clouds). The length of the line depends on the spatial scale of polluted clouds and on the strength of the contrast between polluted and unpolluted clouds. Then we classified pixels in a $60 \mathrm{~km}$ wide segment around the gradient-line as polluted or unpolluted (Fig. 3) following Toll et al. (2019). We calculated the mean reflectance within the first $20 \%$ of the line length, where pixels with lower near-infrared reflectance were situated. Pixels are classified as polluted if their reflectance is two standard deviation above this value and they are situated in the last $40 \%$ of the line length (Fig 3). Because of the 2-sigma criterion, 38 data tracks were discarded, because there was not enough contrast between polluted and unpolluted clouds to include them in the analysis. This way we can be confident that we are looking at aerosol perturbations on clouds. We studied polluted clouds at the $\mathrm{SO}_{2}$ pollution hot spot of the nickel processing site in the city of Norilsk in Russia, and in various continents at major aerosol source regions (Fig. 4). The sulfur dioxide emissions for Norilsk have been estimated to be over 2 Mt per year by Carn et al. (2004). With global anthropogenic $\mathrm{SO}_{2}$ emissions in the order of $100 \mathrm{Mt}$ per year (Smith et al., 2011), this makes Norilsk an extraordinarily strong localized source of $\mathrm{SO}_{2}$. The other regions where polluted clouds have been studied include major industrial regions in Europe, Eastern United States and Eastern Asia. In addition, a few cases where smoke from wildfires have caused changes in cloud properties have been analyzed. These observations sample a wider geographical 
area compared to large-scale cloud perturbations in Moscow area, Russia and Kazakhstan studied by Toll et al. (2019).

We collected 1164 observations of polluted clouds for the Norilsk area, with sampled dates ranging from 2000 to 2017. In addition, we collected 99 observations for various regions for the period of 2012 to 2018 (Fig. 4). The observations from Norilsk are quite evenly distributed over the summer months: from the end of May until the middle of September (Fig. 5). At the latitude of Norilsk, low-level liquid-water clouds are observed mostly only during this warmer time of the year. Non-Norilsk cases are quite evenly distributed over the whole year. Norilsk, being an isolated pollution hot spot, provided suitable observations of pollution-induced steep gradients in cloud droplet size throughout the time series in the warm season (Fig. 5). There are fewer observations for other locations due to more polluted background conditions, which make the polluted cloud areas dimmer. In addition, identifying large scale polluted cloud areas is more difficult compared to identifying ship-track-like perturbations. Meteorological conditions or the amount of pollution are probable reasons for the more numerous observations from Norilsk than from other isolated factories. As we have much fewer observations for non-Norilsk areas, the statistics for these other regions are not as robust as for Norilsk and we concentrate in the analysis only on the data from Norilsk. Still, the analysis of non-Norilsk cases provides additional physical insights, as they show clear bidirectional LWP responses (Table 1).

After classifying satellite pixels as polluted or unpolluted for each segment, we calculate segment-average cloud properties for polluted and unpolluted clouds. For this, we used MODIS cloud products MOD06_L2 (Terra) and MYD06_L2 (Aqua) (Platnick et al., 2017). The 2.1- $\mu$ m near-infrared channel-based cloud properties were used. To ensure that only low-level liquidwater clouds are studied, only pixels with a single layer (cloud multilayer flag $=1$ ) and low-level clouds (cloud top pressure less than $500 \mathrm{hPa}$ ) were included. Pixels for which the cloud phase determined by infrared observations was identified as ice or mixed-phase, and those with ice cloud retrievals were excluded. In order to exclude weak cloud perturbations, we only retained cases where the cloud droplet effective radius was decreased by more than $2 \mu \mathrm{m}$. This is a relatively strong decrease in cloud droplet size, compared to the average cloud droplet effective radius of $16 \mu \mathrm{m}$ observed in unperturbed clouds. In Norilsk, 13 data tracks were filtered out because of the $2 \mu \mathrm{m}$ threshold. It did not have any impact on the mean values in Table 1 . 
To compare meteorological conditions under which the polluted cloud areas were sampled in Norilsk and other areas, MODIS-retrieved cloud top height (CTH) is used. Lower tropospheric stability (LTS) was calculated as the difference between the potential temperature at $700 \mathrm{hPa}$ and the surface. The data for these temperatures and for relative humidity (RH) at $700 \mathrm{hPa}$ was taken from ERA-Interim global atmospheric reanalysis (Dee et al., 2011) We calculated the latitude and longitude of the middle point of the perturbation area and then we defined the area as latitude \pm 0.5 degree and longitude \pm 0.5 degree. We chose the time that was closest to that of the MODIS observation.

\section{Results}

We detected cloud perturbations through the near-infrared signature of changes in cloud droplet effective radius $\left(R_{\text {eff }}\right)$. The frequency distributions of $R_{\text {eff }}$ for polluted and unpolluted clouds reveal nearly distinct distributions (Fig. 6), the $R_{\text {eff }}$ of the polluted clouds is smaller than $12 \mu \mathrm{m}$ in $97 \%$ of cases. In unpolluted clouds, the $\mathrm{R}_{\text {eff }}$ is smaller than $12 \mu \mathrm{m}$ in $13 \%$ of cases. Aerosol pollution decreased the radius of cloud droplets on average by $50 \%$, from $15.9 \mu \mathrm{m}$ down to 7.9 $\mu \mathrm{m}$. Such strong decreases in $\mathrm{R}_{\mathrm{eff}}$ means we are analyzing very strong cloud perturbations, where we can be confident that aerosols have impacted clouds. These strong decreases in $R_{\text {eff }}$ contribute to increased COD and albedo in polluted clouds compared to the unpolluted clouds (Fig. 7).

In agreement with Toll et al. (2017) and Toll et al. (2019), we found that LWP of individual clouds can both significantly increase or decrease as a response to aerosol pollution (Fig. 7). Some of the clouds nearly evaporated, while in other cases the unpolluted LWP was multiplied by up to 8 times. Toll et al. (2019) explained that meteorological conditions control whether LWP increases or decreases in an individual case. Based on Toll et al. (2019) LWP tends to increase in lower, thinner and precipitating clouds and in clouds below moist air and tends to decrease in higher, thicker and non-precipitating clouds and in clouds below dry air. The relative contributions of logarithmic LWP and $\mathrm{R}_{\text {eff }}$ changes to the relative change in COD are given by

$$
\Delta \ln (C O D)=\Delta \ln (L W P)-\Delta \ln \left(R_{e f f}\right)
$$


While by construction (Equation 1) the logarithmic changes in LWP and in $\mathrm{R}_{\text {eff }}$ have the same weight on the relative change in COD, the logarithmic LWP changes are much broader than the changes in $\mathrm{R}_{\text {eff. }}$ Because of that, in most cases, changes in LWP dominate the changes in COD and changes in $\mathrm{R}_{\mathrm{eff}}$ are of secondary importance for COD changes. However, the changes in $\mathrm{R}_{\mathrm{eff}}$ dominate on average, because the changes in LWP closely cancel out each other (Fig. 7). The average COD was increased by $80 \%$ from the average unpolluted value in Norilsk (Table 1). However, in $16 \%$ of cases COD was decreased, meaning a decrease in cloud albedo as well (Fig. 8). In those cases, the decrease in $\mathrm{R}_{\mathrm{eff}}$ increases COD, but the decrease in LWP is so strong that COD decreases overall.

The frequency distribution of relative magnitudes of LWP increases and decreases reveals very close compensation between LWP increases and decreases, both in terms of frequency and magnitude (Fig. 7). On average, LWP decreases by $10 \%$ in the polluted clouds compared to the nearby unpolluted clouds (Table 1). Also, the frequency distributions of polluted and unpolluted LWP, while largely overlapping, show slightly more frequent values of lower LWP for polluted clouds (Fig. 6). The frequency distribution of $-\Delta \ln (\mathrm{COD}) / \Delta \ln \left(\mathrm{R}_{\mathrm{eff}}\right)$ (Equation 1$)$ shows that in individual cases the relative contribution of LWP changes to COD changes is up to four times stronger than the relative contribution through decreased $R_{\text {eff }}$ (Fig 8). But the average value of $-\Delta \ln (\mathrm{COD}) / \Delta \ln \left(\mathrm{R}_{\mathrm{eff}}\right)$ is 0.97 , which is quite close to the value of 1 that indicates no change in LWP on average.

The polluted clouds were sampled under a rather wide range of meteorological conditions (Fig. 9). Even considering the Norilsk cases alone gave that wide range of meteorological conditions but adding non-Norilsk cases extended the range further. Relative humidity was lower for nonNorilsk cases, with an average value of $31 \%$, compared to $52 \%$ at Norilsk. The average lower tropospheric stability was $16.7 \mathrm{~K}$ for non-Norilsk cases, and $13.7 \mathrm{~K}$ for Norilsk. The cloud top was slightly higher on average for non-Norilsk cases with a mean value of $2380 \mathrm{~m}$, compared to $2200 \mathrm{~m}$ at Norilsk. For large-scale cases the dependence of cloud water response on meteorological conditions is noisy so studying meteorological dependence requires a larger number of observations and more automated methods of track detection.

\section{Discussion and conclusions}


We analyzed cloud responses to large-scale aerosol perturbations. The areal extent of the polluted cloud areas detected in MODIS satellite images extended to hundreds by hundreds of kilometers (Fig 1 and 2). Most of the analyzed clouds originated from the aerosol pollution hot spot of nickel processing factories in Norilsk, Russia. We demonstrated that such large-scale aerosol-induced cloud perturbations exist in various regions (Fig 4).

Our analysis of large-scale cloud perturbations supports the close compensation between aerosolinduced cloud water increases and decreases that was previously found in smaller-scale polluted cloud tracks and a limited number of larger-scale polluted cloud areas (Toll et al., 2017; Toll et al., 2019). On average, liquid cloud water response is relatively weak both in the Norilsk area and for non-Norilsk cases collected for various aerosol sources around the world. Still, in individual cases, there can be strong increases or decreases in LWP. The large-scale gradients in cloud droplet size at major aerosol sources analyzed here confirm the existence and importance of the Twomey effect in various regions. Moreover, as the average change in cloud water is small, our analysis supports the dominance of the Twomey effect over the effect of LWP response in the radiative forcing as found in the smaller-scale polluted cloud tracks (Toll et al., 2017; Toll et al., 2019). Our analysis of large-scale cloud perturbations for Norilsk gives an average value of 0.97 for the sensitivity $-\Delta \ln (\mathrm{COD}) / \Delta \ln \left(\mathrm{R}_{\mathrm{eff}}\right)$, meaning that the decrease in LWP offsets $3 \%$ of the radiative forcing through the Twomey effect. Although the estimate of $3 \%$ is much smaller than the previous estimate of $29 \%$ based on smaller-scale pollution tracks by Toll et al. (2019), the variability in LWP responses is too large to assess whether that difference is statistical or due to differences in cloud adjustment processes. Nevertheless, in both cases adjustments are a small fraction of the initial forcing.

The existence of large-scale areas with decreased cloud droplet radii induced by industrial pollution highlights the importance of the Twomey effect in aerosol forcing. The limited number of observations means that they are unlikely to be representative of the globally averaged LWP response. However, the large-scale perturbations studied here are probably more representative of the global average than the smaller-scale polluted clouds that have been used before, so it will be useful to collect a large number of larger-scale perturbations. This study strengthens the conclusion of previous pieces of evidence (Toll et al., 2017; 2019; Malavelle et al. 2017) that rapid adjustments in LWP only provide a relatively weak contribution to the radiative forcing of 
aerosol-cloud interactions. Importantly, a weak average change in LWP does not rule out a strong increase in cloud fraction in response to anthropogenic aerosols (Rosenfeld et al., 2019), so strong global cooling effect caused by cloud adjustments is still possible. Further work will analyze the cloud fraction responses to aerosols in addition to LWP responses.

In the case of smaller-scale polluted cloud tracks like in Toll et al. (2019), the polluted clouds can be linked to a single aerosol point source. Linking polluted clouds to a single source of air pollution is more difficult in the case of larger-scale cloud perturbations. In the Norilsk area, it was possible to link polluted clouds to nickel production factories thanks to the strong contrast in cloud droplet radii between the polluted and nearby unpolluted clouds. In other regions, we were not able to pin-point a single pollution source responsible for the cloud perturbation in each case. Instead, multiple aerosol sources or even larger industrial regions were most probably responsible for the decreased cloud droplet radii. Still, there could be other factors contributing to differences in cloud properties. We cannot entirely exclude the potential contribution of urban heat islands or differences in surface characteristics in urban areas compared to the nearby rural areas to the differences in cloud properties but note that the observed reduction in cloud droplet effective radius follows our expectations of the physics of the Twomey effect. Aerosol above clouds can impact satellite retrievals (Peers et al., 2019), and this can potentially have some impact on our analyses.

Our finding of a weak average LWP change in response to aerosols strongly disagrees with the assumption of universally increased LWP used in global climate models (Quaas et al., 2009, Ghan et al., 2016; Mulcahy et al., 2018; Gettelman et al.,2019). In addition to adding to existing pieces of evidence challenging the unidirectional LWP increases assumed in GCMs (Malavelle et al., 2017; Toll et al., 2019), the large-scale aerosol-induced cloud perturbations studied here are especially useful in a GCM context because they cover the area of several grid boxes of a typical current GCM. Our analysis of large-scale polluted cloud areas indicates that the differences between LWP responses in models and observations are not due to scale issues. The satellite observations of polluted clouds analyzed here can help to improve physical parameterizations used in GCMs and lead to more reliable projections of the future climate. Although the total number of sampled large-scale cloud perturbations is still limited, these observations could be used for process-scale studies about aerosol impacts on clouds. The 
number of the polluted cloud areas could be increased in the future using machine learning methods to detect polluted clouds in the satellite images automatically (Yuan et al., 2019).

\section{Acknowledgments and data availability}

This study was funded by the Estonian Research Council personal research funding grant PSG202.The RGB images (MODIS channels 3-6-7) used for the visual detection of polluted clouds from https://worldview.earthdata.nasa.gov/ were used. The MODIS timestamps and locations of the studied cloud perturbations are available at http://datadoi.ee/handle/33/190. The MODIS cloud products MYD06_L2 from Aqua and MOD06_L2 from Terra used in this study are available from the Atmosphere Archive and Distribution System (LAADS) Distributed Active Archive Center (DAAC), https://ladsweb.nascom.nasa.gov/. The temperature and relative humidity data used in this study is available from ERA-Interim global atmospheric reanalysis, https://www.ecmwf.int/en/forecasts/datasets/reanalysis-datasets/era-interim.

\section{Author contributions}

VT designed the study. HT identified the polluted cloud areas in the satellite images and analyzed the observations. All authors contributed to the writing of the manuscript.

\section{References}

Ackerman, A. S., Kirkpatrick, M. P., Stevens, D. E., \& Toon, O. B. (2004). The impact of humidity above stratiform clouds on indirect aerosol climate forcing. Nature, 432(7020), 1014.

Albrecht, B. A. (1989). Aerosols, cloud microphysics, and fractional cloudiness. Science, 245(4923), 1227-1230.

Bellouin, N., Quaas, J., Gryspeerdt, E., Kinne, S., Stier, P., Watson-Parris, D., ... \& Dufresne, J. L. (2019). Bounding global aerosol radiative forcing of climate change. Reviews of Geophysics.

Boucher, O., Randall, D., Artaxo, P., Bretherton, C., Feingold, G., Forster, P., ... \& Rasch, P. (2013). Clouds and aerosols. In Climate change 2013: the physical science basis. Contribution of Working Group I to the Fifth Assessment Report of the Intergovernmental Panel on Climate Change (pp. 571-657). Cambridge University Press. 
Bretherton, C. S., Blossey, P. N., \& Uchida, J. (2007). Cloud droplet sedimentation, entrainment efficiency, and subtropical stratocumulus albedo. Geophysical research letters, 34(3).

Carn, S. A., Krueger, A. J., Krotkov, N. A., \& Gray, M. A. (2004). Fire at Iraqi sulfur plant emits SO2 clouds detected by Earth Probe TOMS. Geophysical research letters, 31(19).

Coakley, J. A., Bernstein, R. L., \& Durkee, P. A. (1987). Effect of ship-stack effluents on cloud reflectivity. Science, 237(4818), 1020-1022.

Dee, D. P., Uppala, S. M., Simmons, A. J., Berrisford, P., Poli, P., Kobayashi, S., ... \& Bechtold, P. (2011). The ERA-Interim reanalysis: Configuration and performance of the data assimilation system. Quarterly Journal of the royal meteorological society, 137(656), 553-597.

Gettelman, A., Mills, M. J., Kinnison, D. E., Garcia, R. R., Smith, A. K., Marsh, D. R., ... \& Liu, H. L. (2019). The Whole Atmosphere Community Climate Model Version 6 (WACCM6). Journal of Geophysical Research: Atmospheres, 124(23), 12380-12403.

Ghan, S., Wang, M., Zhang, S., Ferrachat, S., Gettelman, A., Griesfeller, J., ... \& Partridge, D. G. (2016). Challenges in constraining anthropogenic aerosol effects on cloud radiative forcing using present-day spatiotemporal variability. Proceedings of the National Academy of Sciences, $113(21), 5804-5811$.

Gryspeerdt, E., Goren, T., Sourdeval, O., Quaas, J., Mülmenstädt, J., Dipu, S., ... \& Christensen, M. (2019). Constraining the aerosol influence on cloud liquid water path. Atmospheric Chemistry and Physics, 19(8), 5331-5347.

Hill, A. A., Feingold, G., \& Jiang, H. (2009). The influence of entrainment and mixing assumption on aerosol-cloud interactions in marine stratocumulus. Journal of the Atmospheric Sciences, 66(5), 1450-1464.

Malavelle, F. F., Haywood, J. M., Jones, A., Gettelman, A., Clarisse, L., Bauduin, S., ... \& Cho, N. (2017). Strong constraints on aerosol-cloud interactions from volcanic eruptions. Nature, 546(7659), 485.

McCoy, D. T., Field, P., Gordon, H., Elsaesser, G. S., \& Grosvenor, D. P. Untangling causality in midlatitude aerosol-cloud adjustments.

Mulcahy, J. P., Jones, C., Sellar, A., Johnson, B., Boutle, I. A., Jones, A., ... \& Johnson, C. E. (2018). Improved aerosol processes and effective radiative forcing in HadGEM3 and UKESM1. Journal of Advances in Modeling Earth Systems, 10(11), 2786-2805.

Mülmenstädt, J., \& Feingold, G. (2018). The radiative forcing of aerosol-cloud interactions in liquid clouds: wrestling and embracing uncertainty. Current Climate Change Reports, 4(1), 2340 .

Peers, F., Francis, P., Fox, C., Abel, S. J., Szpek, K., Cotterell, M. I., ... \& Haywood, J. M. (2019). Observation of absorbing aerosols above clouds over the south-east Atlantic Ocean from the geostationary satellite SEVIRI-Part 1: Method description and sensitivity. 
Platnick, S., Meyer, K. G., King, M. D., Wind, G., Amarasinghe, N., Marchant, B., ... \& Yang, P. (2016). The MODIS cloud optical and microphysical products: Collection 6 updates and examples from Terra and Aqua. IEEE Transactions on Geoscience and Remote Sensing, 55(1), $502-525$.

Possner, A., Wang, H., Wood, R., Caldeira, K., \& Ackerman, T. P. (2018). The efficacy of aerosol-cloud radiative perturbations from near-surface emissions in deep open-cell stratocumuli. Atmospheric Chemistry and Physics, 18(PNNL-SA-140346).

Rosenfeld, D., Zhu, Y., Wang, M., Zheng, Y., Goren, T., \& Yu, S. (2019). Aerosol-driven droplet concentrations dominate coverage and water of oceanic low-level clouds. Science, 363(6427), eaav0566.

Quaas, J., Ming, Y., Menon, S., Takemura, T., Wang, M., Penner, J. E., ... \& Sayer, A. M. (2009). Aerosol indirect effects-general circulation model intercomparison and evaluation with satellite data. Atmospheric Chemistry and Physics, 9(22), 8697-8717.

Small, J. D., Chuang, P. Y., Feingold, G., \& Jiang, H. (2009). Can aerosol decrease cloud lifetime?. Geophysical Research Letters, 36(16).

Smith, S. J., Aardenne, J. V., Klimont, Z., Andres, R. J., Volke, A., \& Delgado Arias, S. (2011). Anthropogenic sulfur dioxide emissions: 1850-2005. Atmospheric Chemistry and Physics, 11(3), 1101-1116.

Stevens, B., Sherwood, S. C., Bony, S., \& Webb, M. J. (2016). Prospects for narrowing bounds on Earth's equilibrium climate sensitivity. Earth's Future, 4(11), 512-522.

Toll, V., Christensen, M., Gassó, S., \& Bellouin, N. (2017). Volcano and Ship Tracks Indicate Excessive Aerosol-Induced Cloud Water Increases in a Climate Model. Geophysical research letters, 44(24), 12-492.

Toll, V., Christensen, M., Quaas, J., \& Bellouin, N. (2019). Weak average liquid-cloud-water response to anthropogenic aerosols. Nature, 572(7767), 51.

Twomey, S. (1974). Pollution and the planetary albedo. Atmospheric Environment (1967), 8(12), 1251-1256.

Walter, D., Heue, K. P., Rauthe-Schöch, A., Brenninkmeijer, C. A. M., Lamsal, L. N., Krotkov, N. A., \& Platt, U. (2012). Flux calculation using CARIBIC DOAS aircraft measurements: SO2 emission of Norilsk. Journal of Geophysical Research: Atmospheres, 117(D11).

Yuan, T., Wang, C., Song, H., Platnick, S., Meyer, K., \& Oreopoulos, L. (2019). Automatically Finding Ship-tracks to Enable Large-scale Analysis of Aerosol-Cloud Interactions. Geophysical Research Letters. 

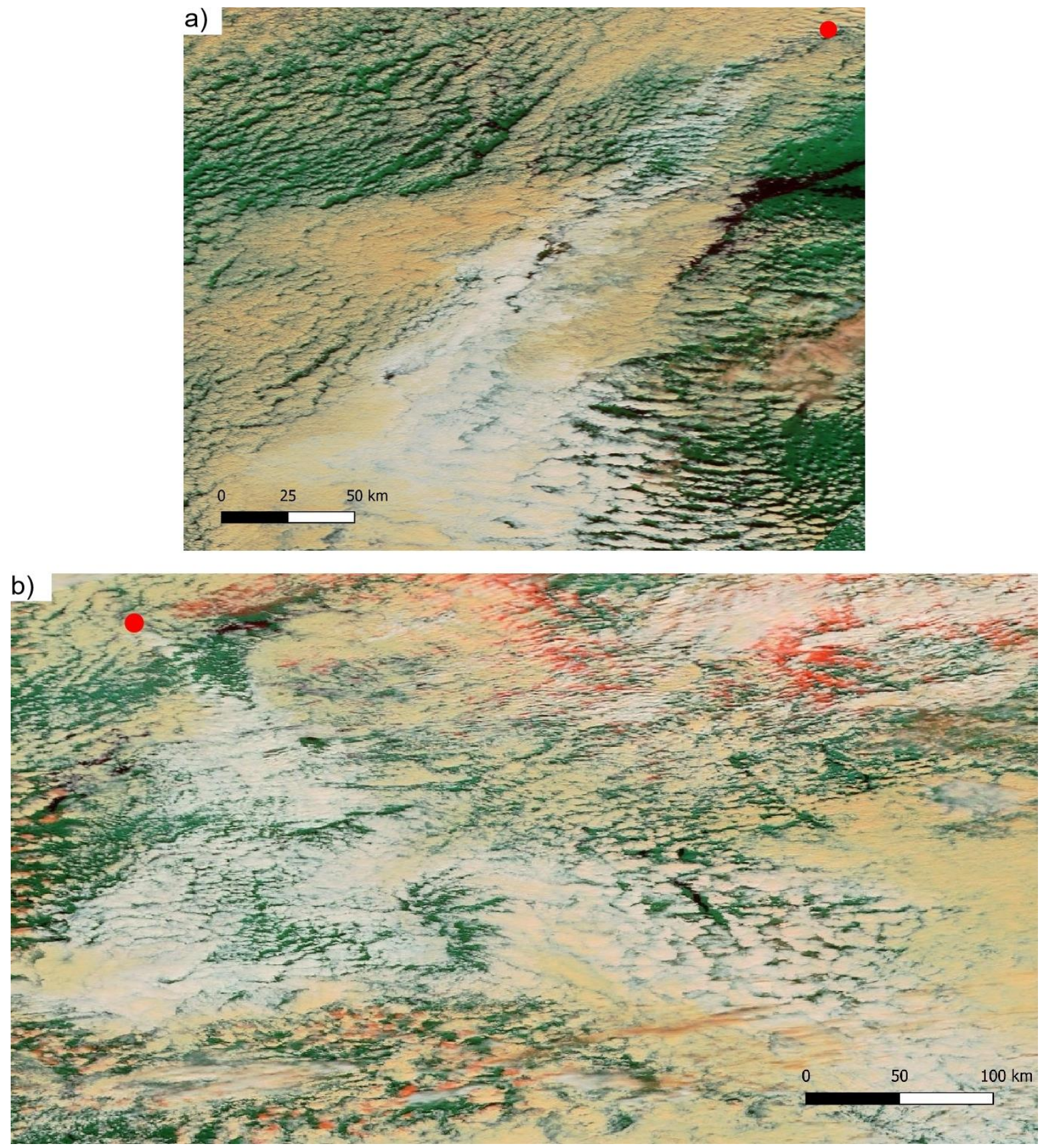

Figure 1. Examples of polluted clouds at Norilsk as seen from MODIS near-infrared composite satellite images. Polluted clouds are shown in grey-white colors and unpolluted clouds in yellowbrown colors. Green color that can be seen from the cloud-free areas is vegetation. Red color indicates the presence of ice or snow. The aerosols inducing the polluted cloud area originate from Norilsk factories, which are marked with a red dot. (a) Image was taken on August 26, 2006. The image covers area bounded by $83.3^{\circ} \mathrm{E}$ and $88.2^{\circ} \mathrm{E}$ in longitude and $65.3^{\circ} \mathrm{N}$ and $69.6^{\circ} \mathrm{N}$ in latitude. The maximum length and width of the track are $511 \mathrm{~km}$ and $145 \mathrm{~km}$. (b) Image was taken on June 27,2000 . The image covers area bounded by $86.8^{\circ} \mathrm{E}$ and $97.5^{\circ} \mathrm{E}$ in longitude and $63.9^{\circ} \mathrm{N}$ and $69.9^{\circ} \mathrm{N}$ in latitude. The Maximum length and width of the track are $415 \mathrm{~km}$ and 215 $\mathrm{km}$. 

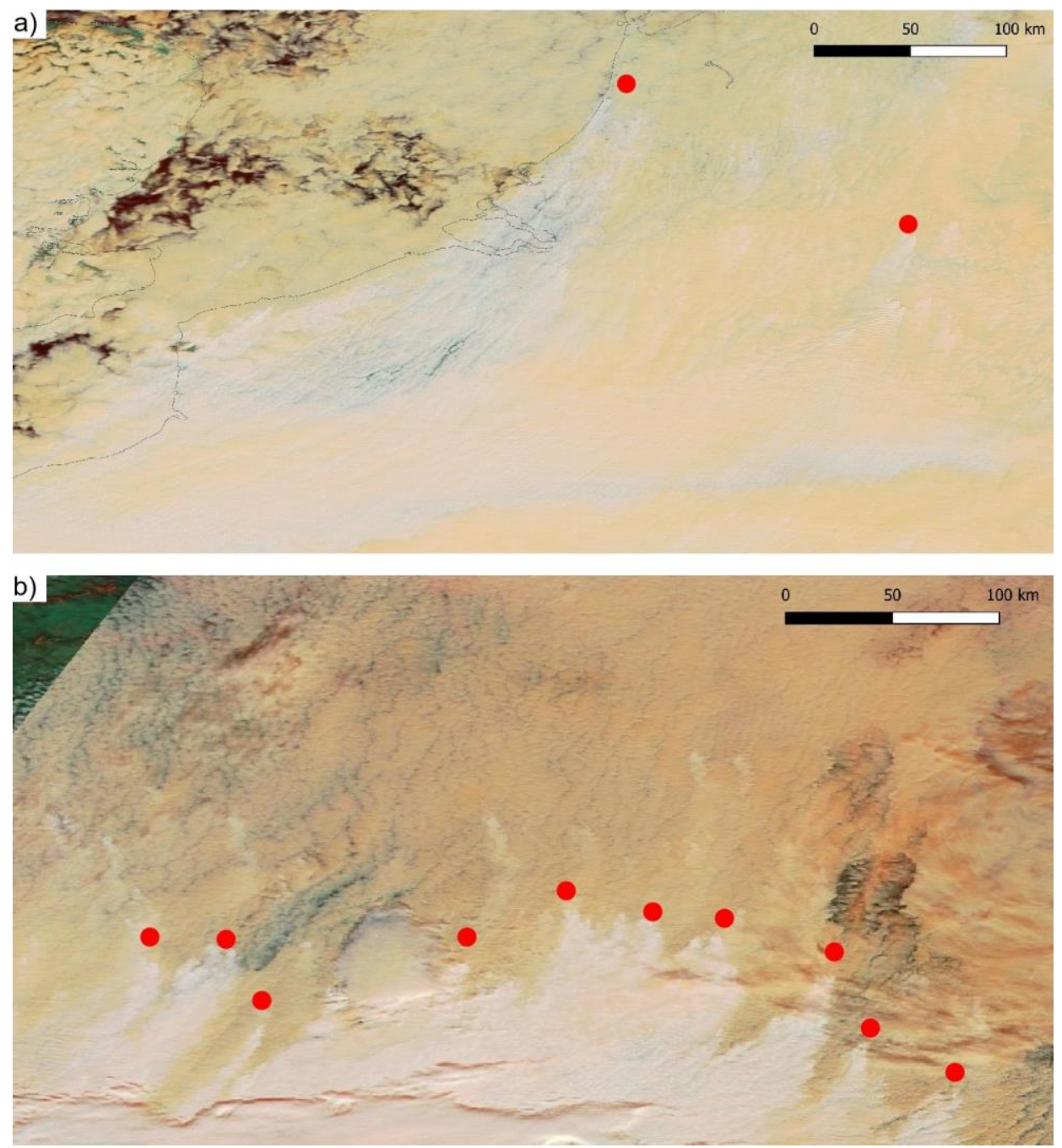

Figure 2. Further examples of polluted clouds. Polluted clouds are shown in grey-white colors and unpolluted clouds in yellow-brown colors. Red dots mark approximate locations of aerosol sources that induce the polluted cloud areas. Only parts of the sources are shown for illustration.

398 (a) Pollution downwind of urban and industrial sources in Europe, March 19, 2016. The image covers area bounded by $0.5^{\circ} \mathrm{E}$ and $7.9^{\circ} \mathrm{E}$ in longitude and $49.2^{\circ} \mathrm{N}$ and $53.1^{\circ} \mathrm{N}$ in latitude. The maximum length and width of the track are $330 \mathrm{~km}$ and $130 \mathrm{~km}$. (b) Clouds polluted by wildfire smoke in Russia, September 30, 2016. The image covers area bounded by $97.6^{\circ} \mathrm{E}$ and $106.2^{\circ} \mathrm{E}$ in longitude and $57^{\circ} \mathrm{N}$ and $64^{\circ} \mathrm{N}$ in latitude. The maximum length and width of the track are 320

$403 \mathrm{~km}$ and $566 \mathrm{~km}$ 
a)

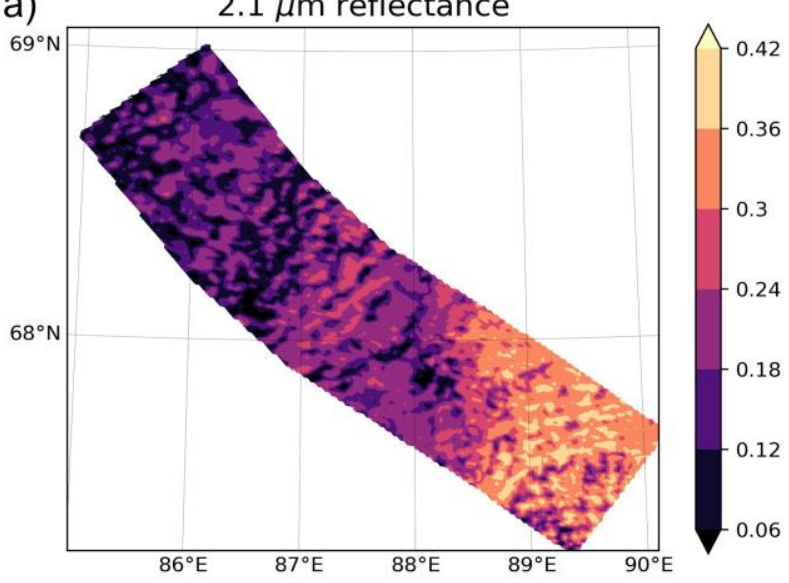

c)

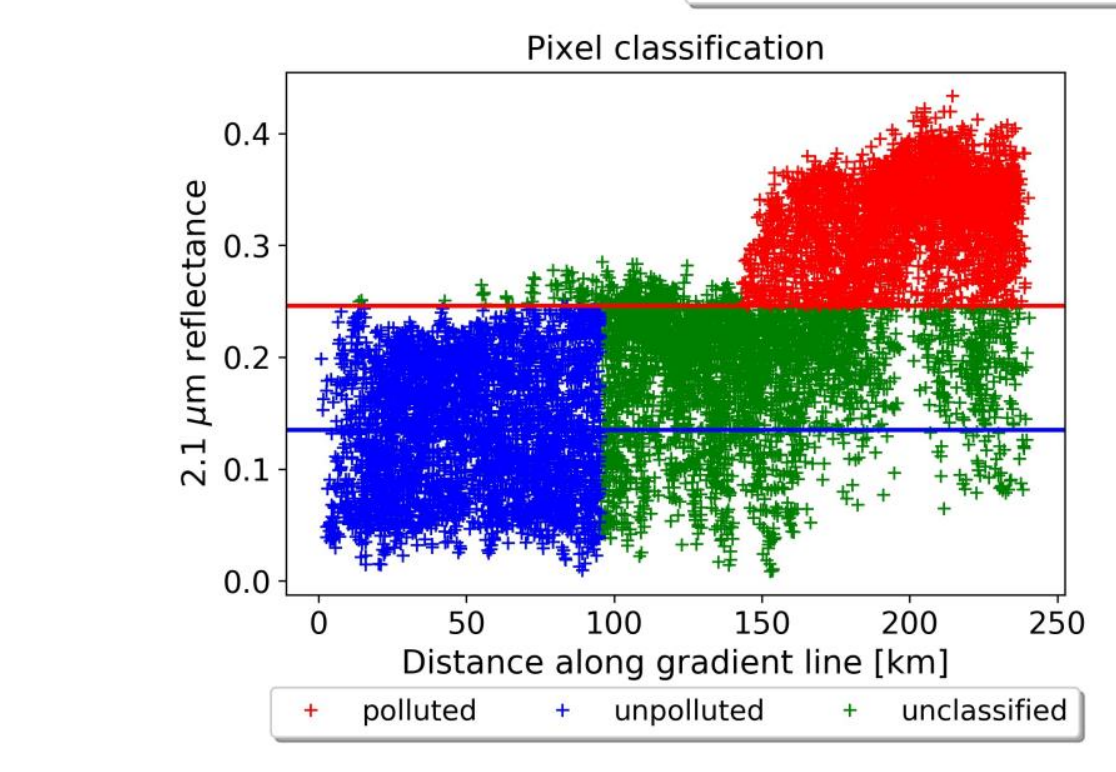

)

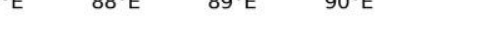

Pixel classification b)

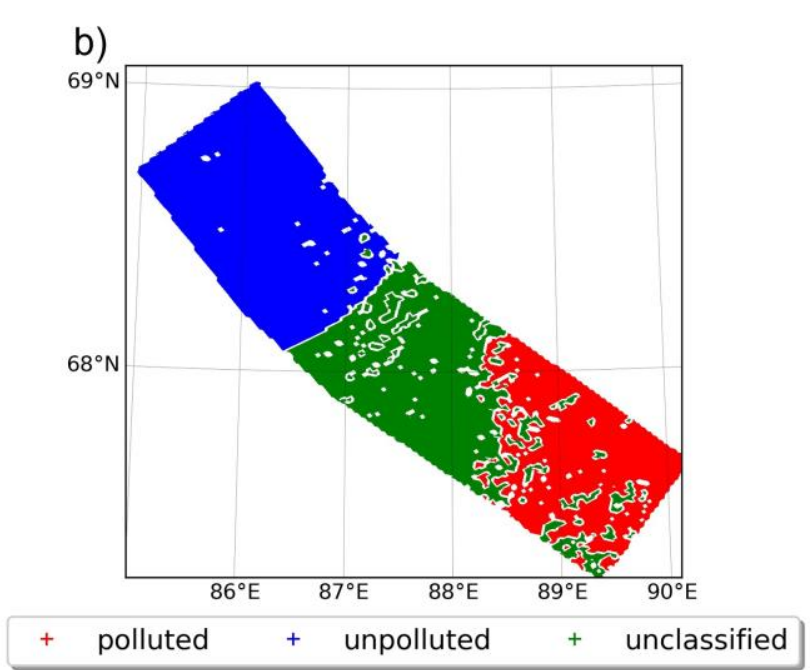

Figure 3. Classification of pixels as polluted and unpolluted. (a) A line was drawn on the 2.1$\mu \mathrm{m}$ reflectance image, starting from the unpolluted clouds with lower reflectance and ending in the polluted clouds with elevated reflectance. A $60-\mathrm{km}$ wide segment around the line was analyzed. (b) Pixels in this segment were classified as polluted (red) or unpolluted (blue). The green pixels are not included in the analysis. (c) The blue line is the mean reflectance within the first $20 \%$ of the line length from the starting point, i.e. within the unpolluted clouds. The red line is two standard deviations above the blue line. Pixels are classified as polluted (red) if their reflectance is above the red line and situated in the last $40 \%$ of the track, and classified as unpolluted (blue), if their reflectance is under the red line and in the first $40 \%$ of the track. 


\section{Confidential manuscript submitted to JGR Atmospheres}

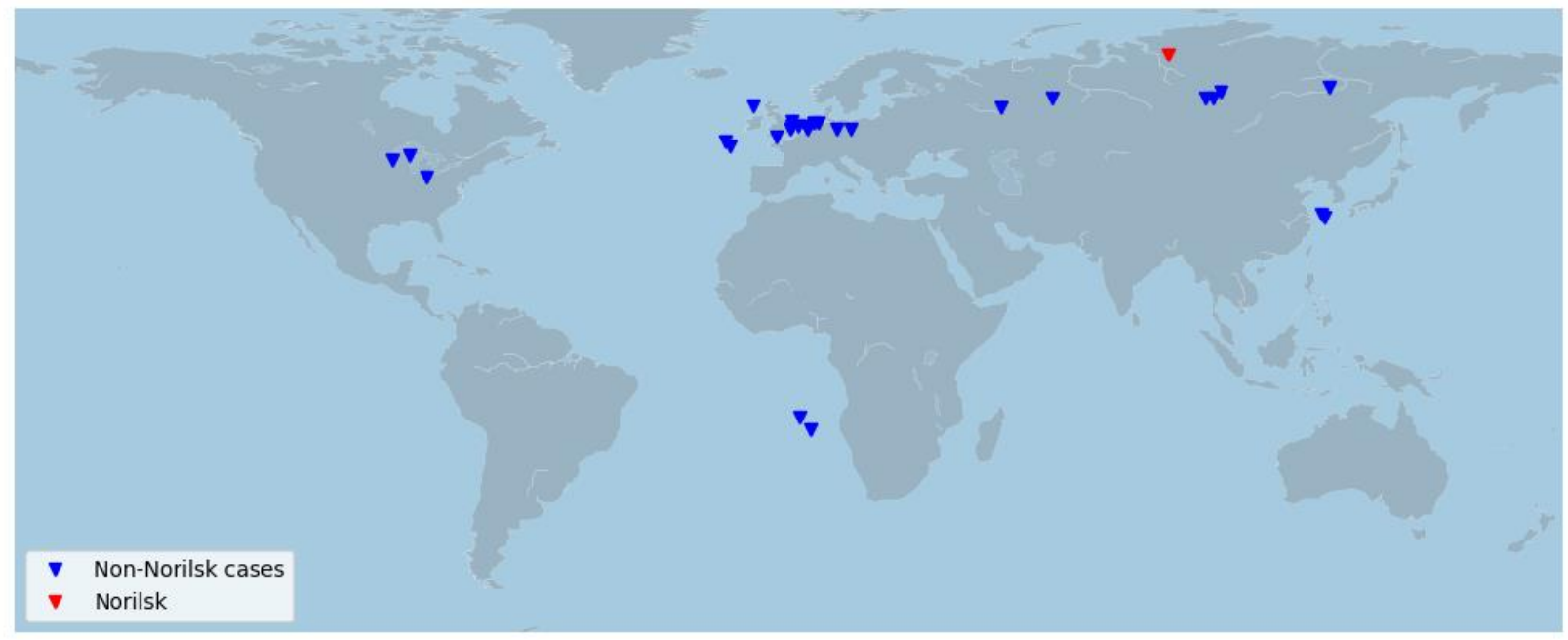

416

417

Figure 4. The locations of analyzed polluted clouds.

418 


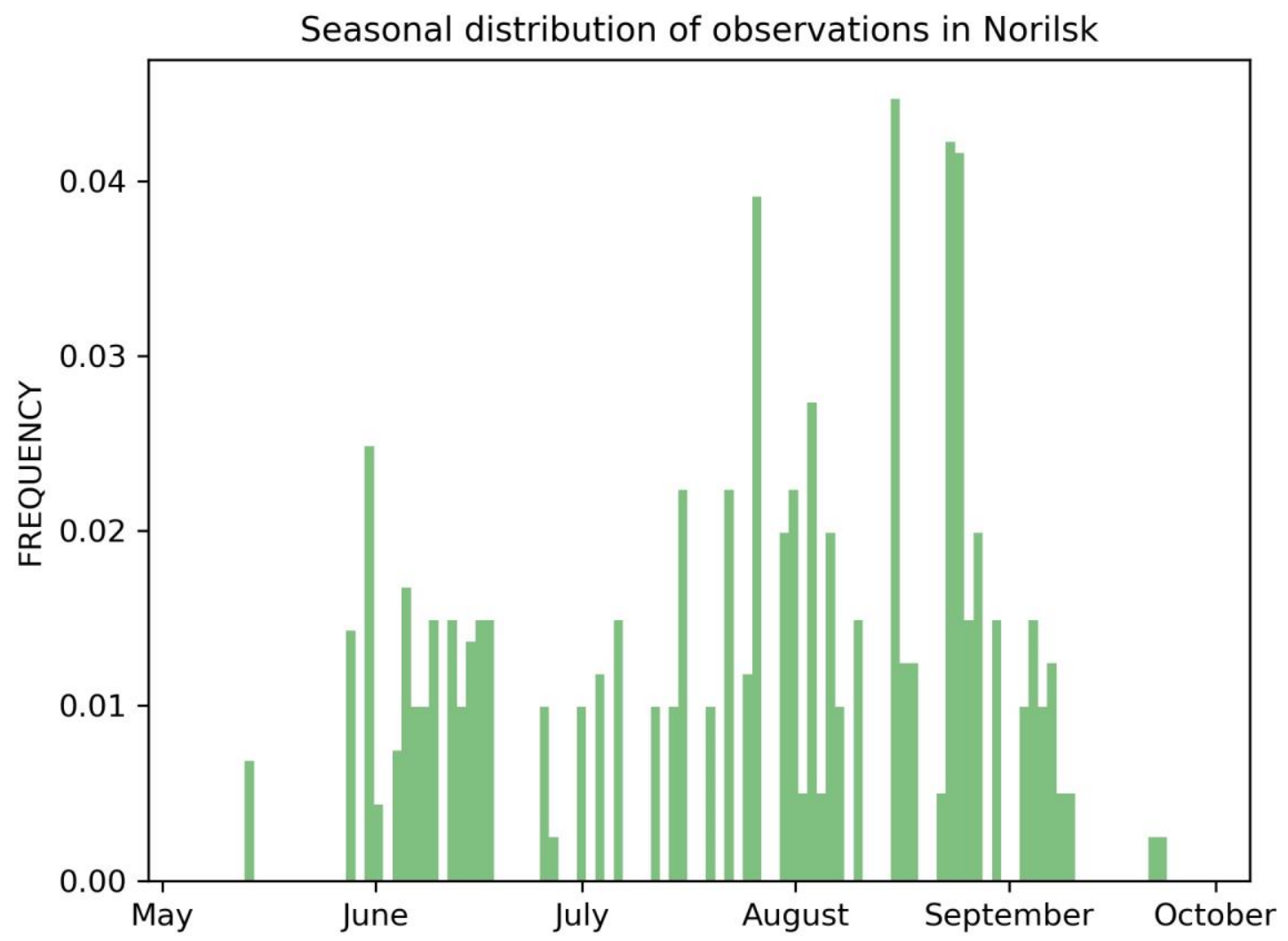

\section{$420 \quad$ Figure 5}

421 Seasonal distribution of observations in Norilsk. All Norilsk cases are included in this figure 422 (there were no cases from October until the middle of May). 
426
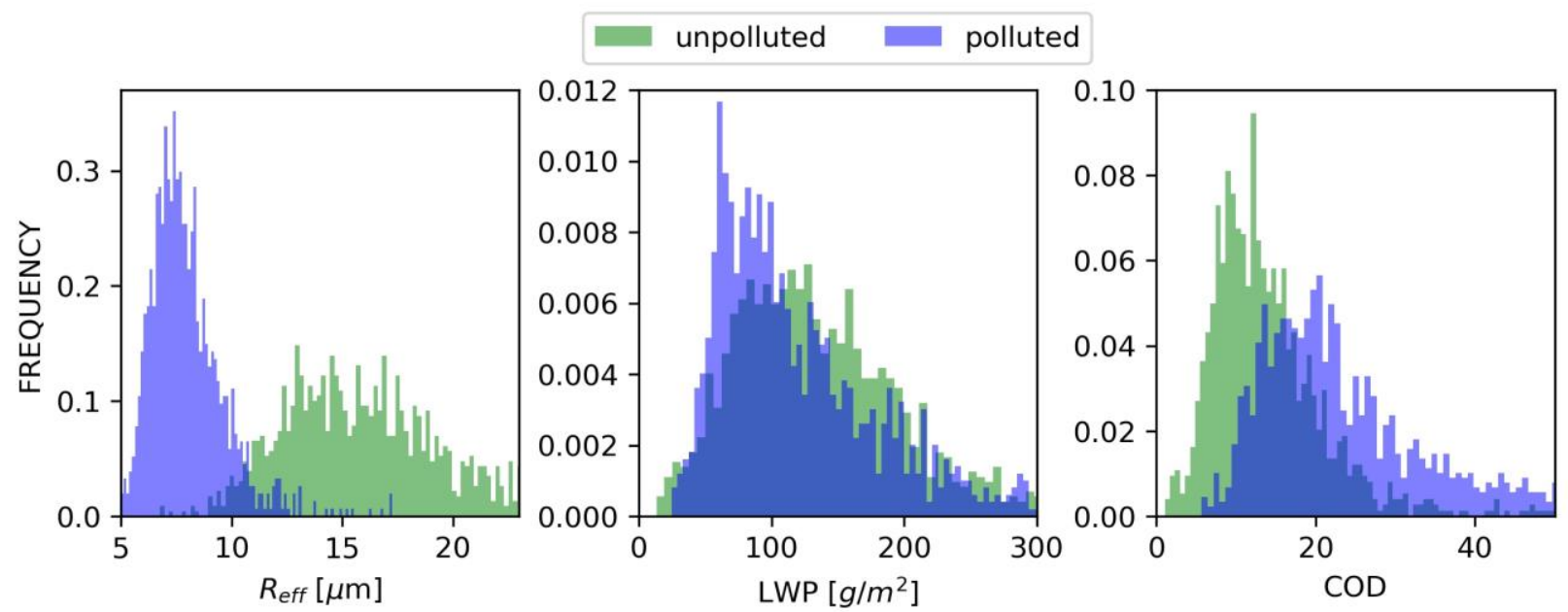

Figure 6. Frequency distributions of cloud droplet effective radius $\left(\mathrm{R}_{\mathrm{eff}}\right)$, liquid water path (LWP) and cloud optical depth (COD) for polluted and unpolluted clouds in Norilsk. 


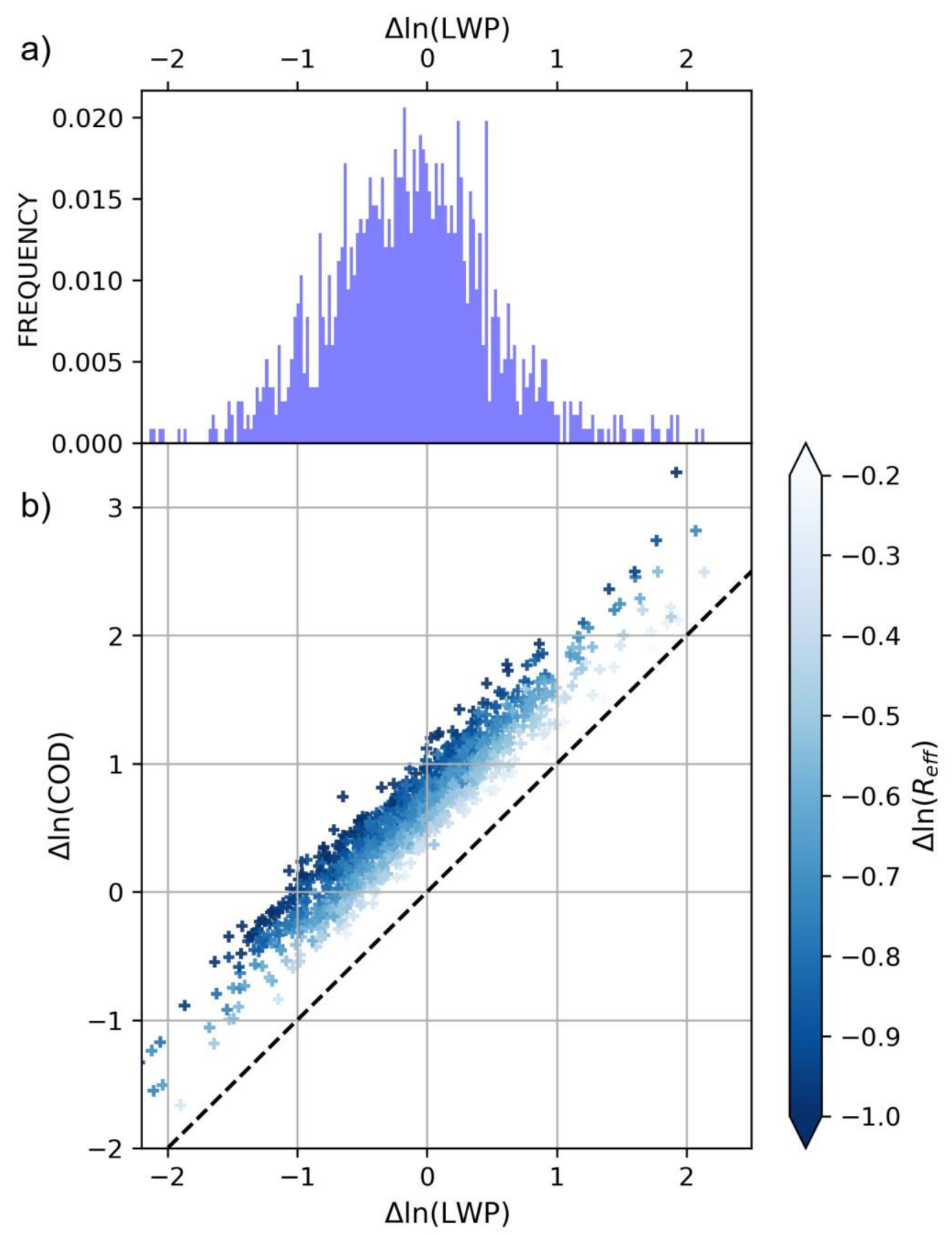

$432 \quad$ Figure 7. (b) Susceptibility of cloud optical depth (COD) to liquid water path ( $L W P)$ changes in 433 Norilsk. The logarithmic changes in cloud droplet effective radii $\left(R_{e f f}\right)$ for individual tracks are 434 given in color. The dashed line is the $C O D$ susceptibility to $L W P$ changes if there were no changes in $R_{\text {eff. }}$ (a) Frequency distribution of $\Delta \ln (L W P)$. 


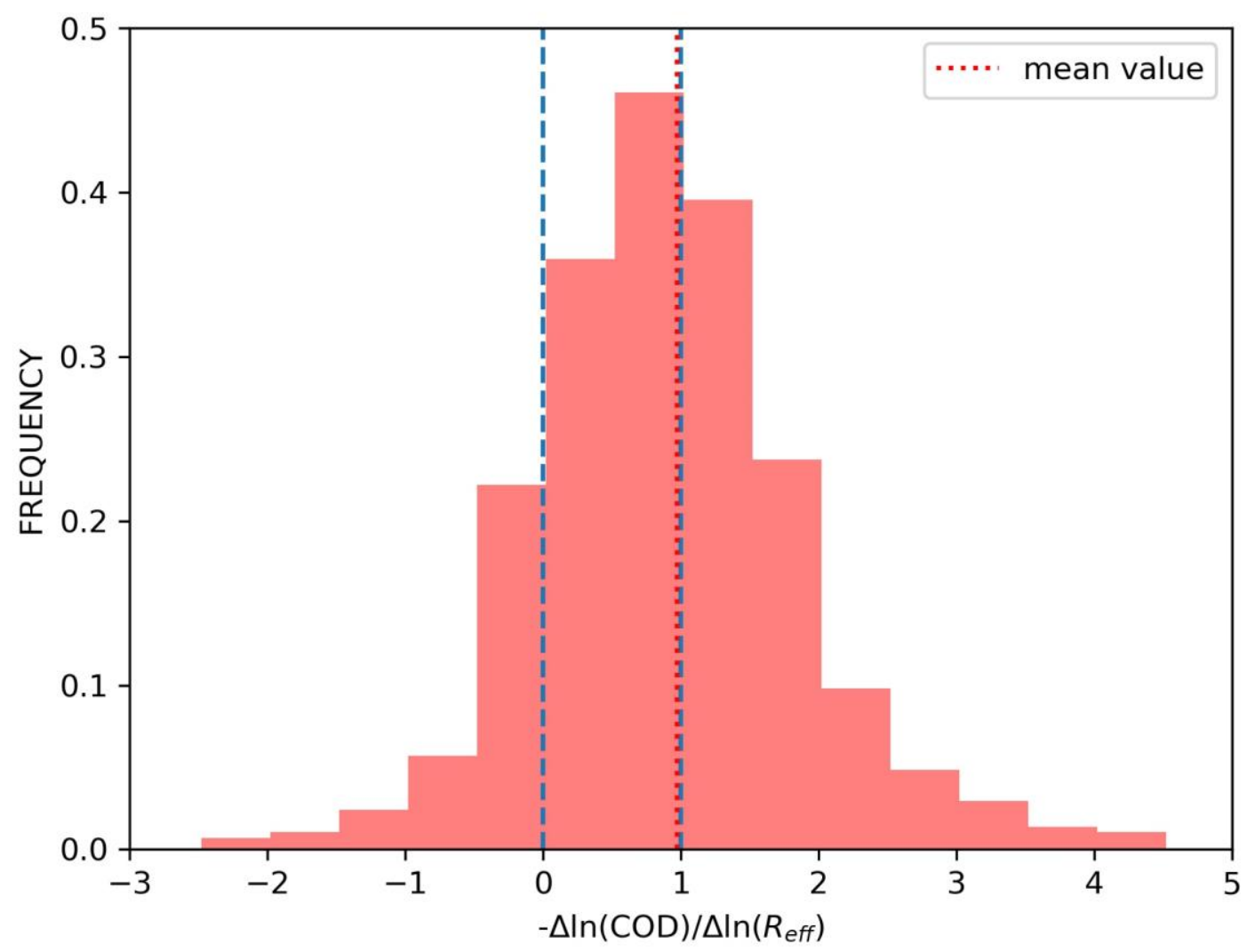

Figure 8. Frequency distribution for $-\Delta / n(C O D) / \Delta l n\left(R_{e f f}\right)$ in Norilsk, where $C O D$ is cloud optical depth and $R_{\text {eff }}$ is cloud droplet effective radius. The bin width is 0.5 . The mean value of $-\Delta \ln (C O D) / \Delta \ln \left(R_{e f f}\right)$ is 0.97 . Liquid water path is increased in polluted clouds if this ratio is larger than 1 and decreased otherwise. If this ratio is less than than 0 , then the $C O D$ and the cloud albedo is decreased in the polluted clouds. The values of zero and one are marked with the blue dashed lines.The cloud albedo was decreased in $16.4 \%$ of cases. $44 \%$ of cases are right of the 1 line. 
447

448

449

450

451
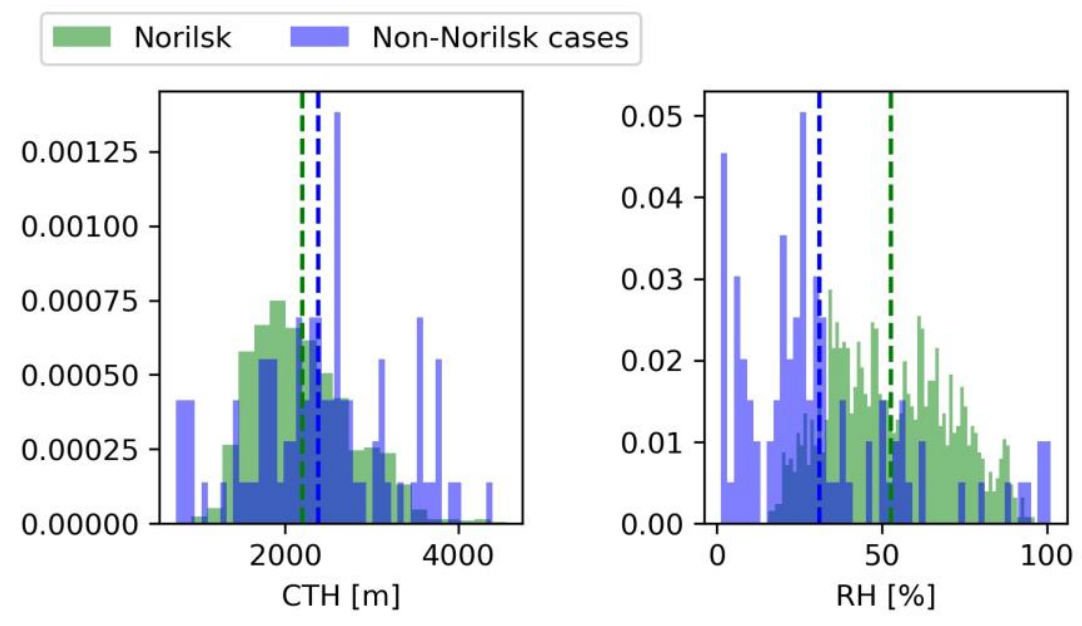

Figure 9. Meteorological conditions for cases with polluted clouds: lower tropospheric stability (LTS) [K], cloud top height $(\mathrm{CTH})[\mathrm{m}]$, relative humidity $(\mathrm{RH})[\%]$ at $700 \mathrm{hPa}$. 
452 Table 1. Average cloud droplet effective radius $\left(\mathrm{R}_{\text {eff }}\right)$, liquid water path (LWP) and cloud optical 453 depth (COD) of polluted and unpolluted clouds. All cases include observations both from 454 Norilsk and non-Norilsk cases. Standard deviation is given in the parenthesis.

455

\begin{tabular}{|c|c|c|c|c|c|c|c|c|c|}
\hline & \multicolumn{3}{|c|}{ Norilsk cases (1164) } & \multicolumn{3}{|c|}{ Non-Norilsk cases (99) } & \multicolumn{3}{|c|}{ All cases (1263) } \\
\hline & $\begin{array}{l}\text { Unpolluted } \\
\text { area }\end{array}$ & $\begin{array}{l}\text { Polluted } \\
\text { area }\end{array}$ & $\begin{array}{l}\text { Fractional } \\
\text { change }\end{array}$ & $\begin{array}{l}\text { Unpolluted } \\
\text { area }\end{array}$ & $\begin{array}{l}\text { Polluted } \\
\text { area }\end{array}$ & $\begin{array}{l}\text { Fractional } \\
\text { change }\end{array}$ & $\begin{array}{l}\text { Unpolluted } \\
\text { area }\end{array}$ & $\begin{array}{l}\text { Polluted } \\
\text { area }\end{array}$ & $\begin{array}{l}\text { Fractional } \\
\text { change }\end{array}$ \\
\hline $\mathrm{R}_{\mathrm{eff}}$ & $15.9(4)$ & $7.9(2)$ & -0.5 & $14.4(3)$ & $8.4(2)$ & -0.4 & $15.8(4)$ & $7.9(2)$ & -0.5 \\
\hline LWP & $142.0(80)$ & $\begin{array}{l}125.6 \\
(74) \\
\end{array}$ & -0.1 & $184.5(79)$ & $\begin{array}{l}141.0 \\
(71)\end{array}$ & -0.2 & $145.3(81)$ & $\begin{array}{l}126.8 \\
(74)\end{array}$ & -0.1 \\
\hline COD & $14.1(8)$ & $25.6(15)$ & +0.8 & $21.6(12)$ & $26.8(12)$ & +0.2 & $14.6(8)$ & $25.7(15)$ & +0.8 \\
\hline
\end{tabular}


Figure 1. 
Figure 2. 
Figure 3. 
a)

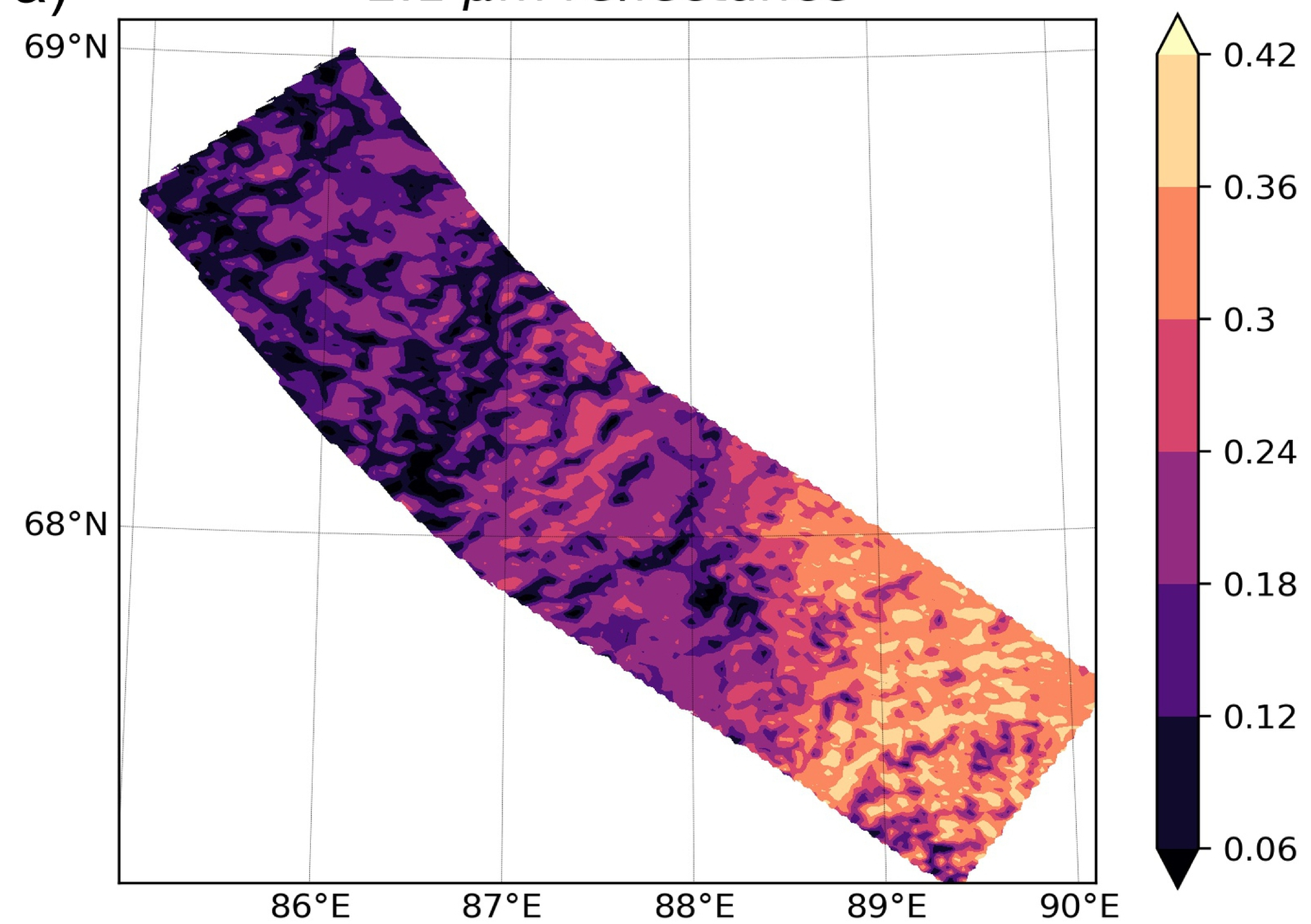

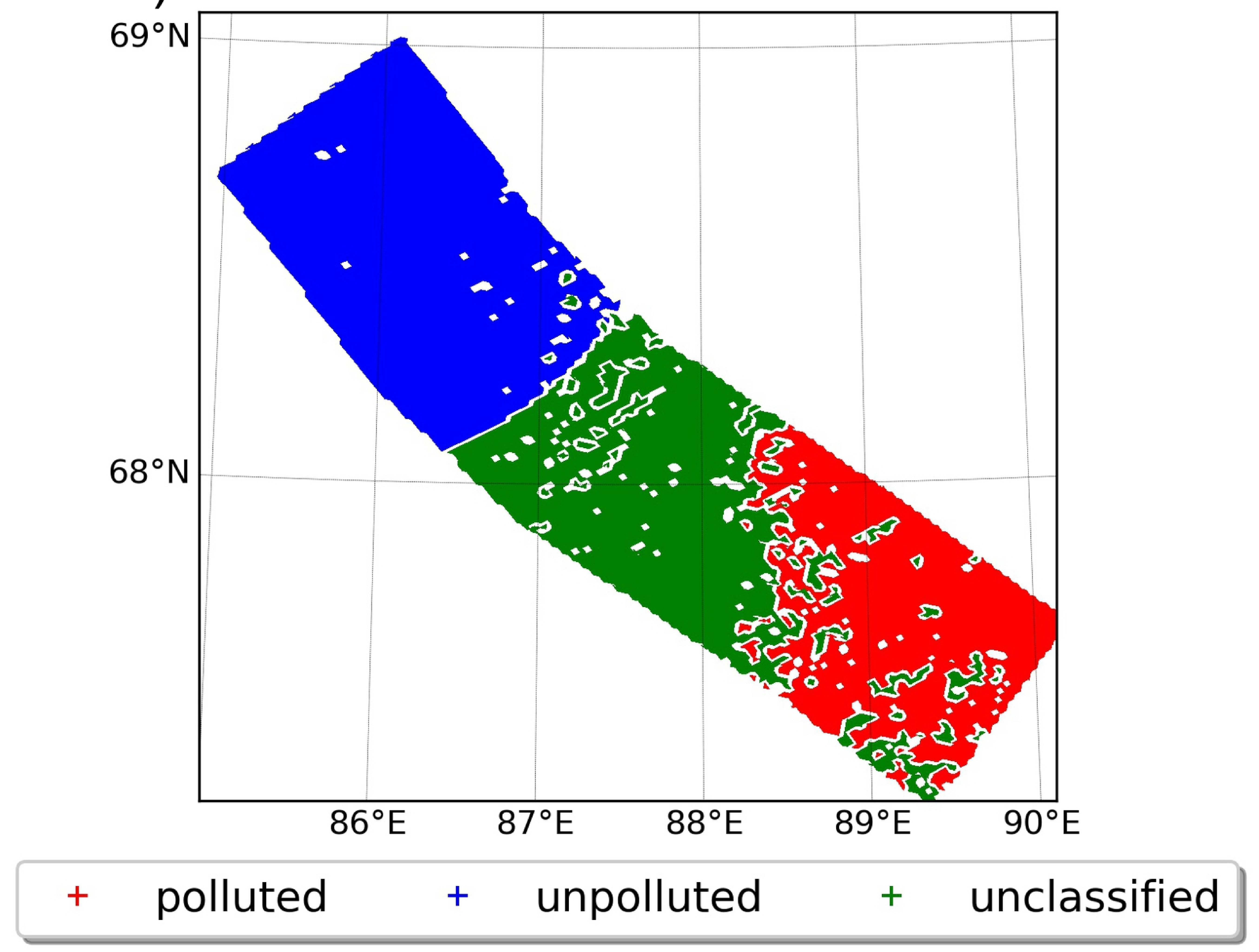

C)

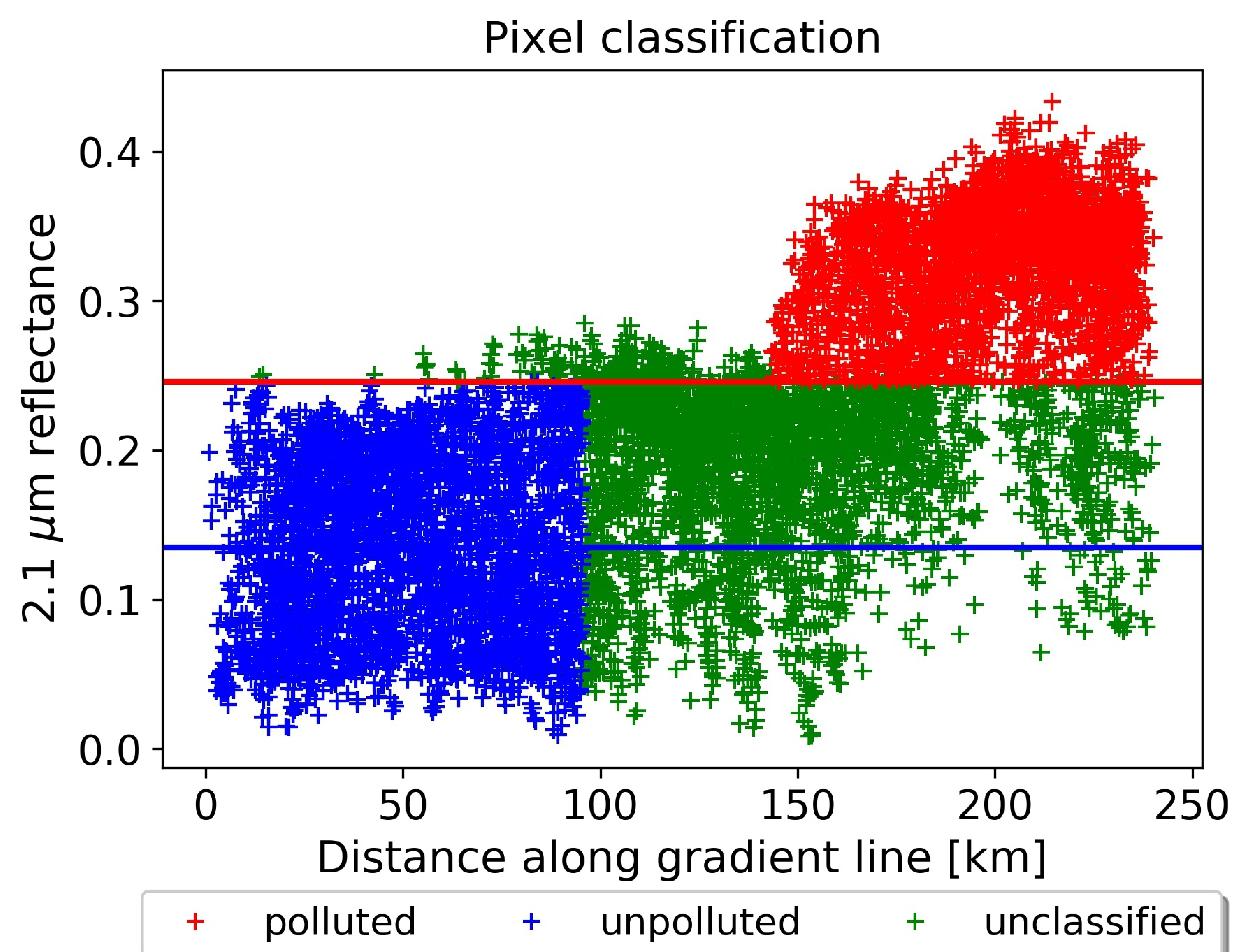


Figure 4. 

Figure 5. 
Seasonal distribution of observations in Norilsk

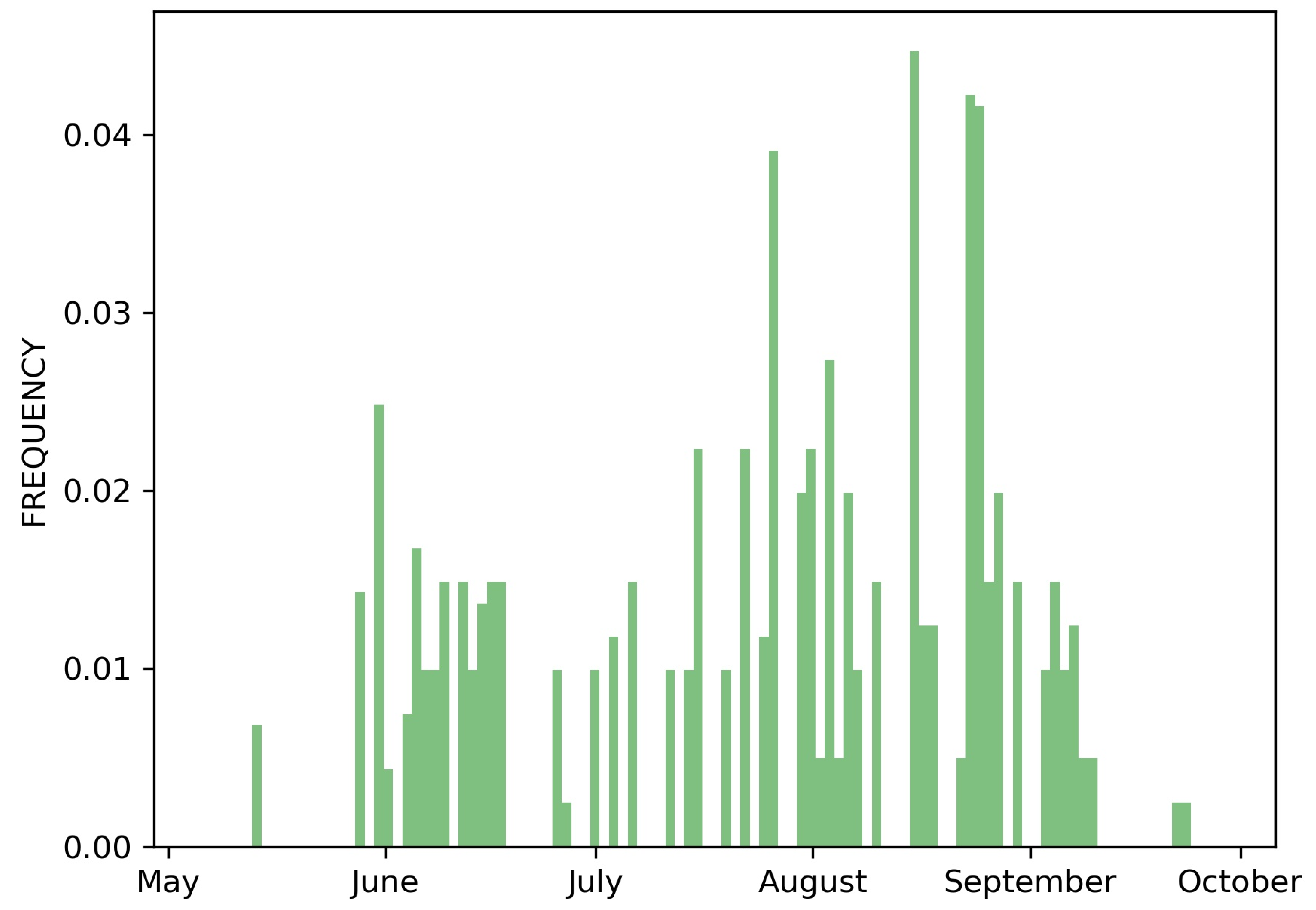


Figure 6. 

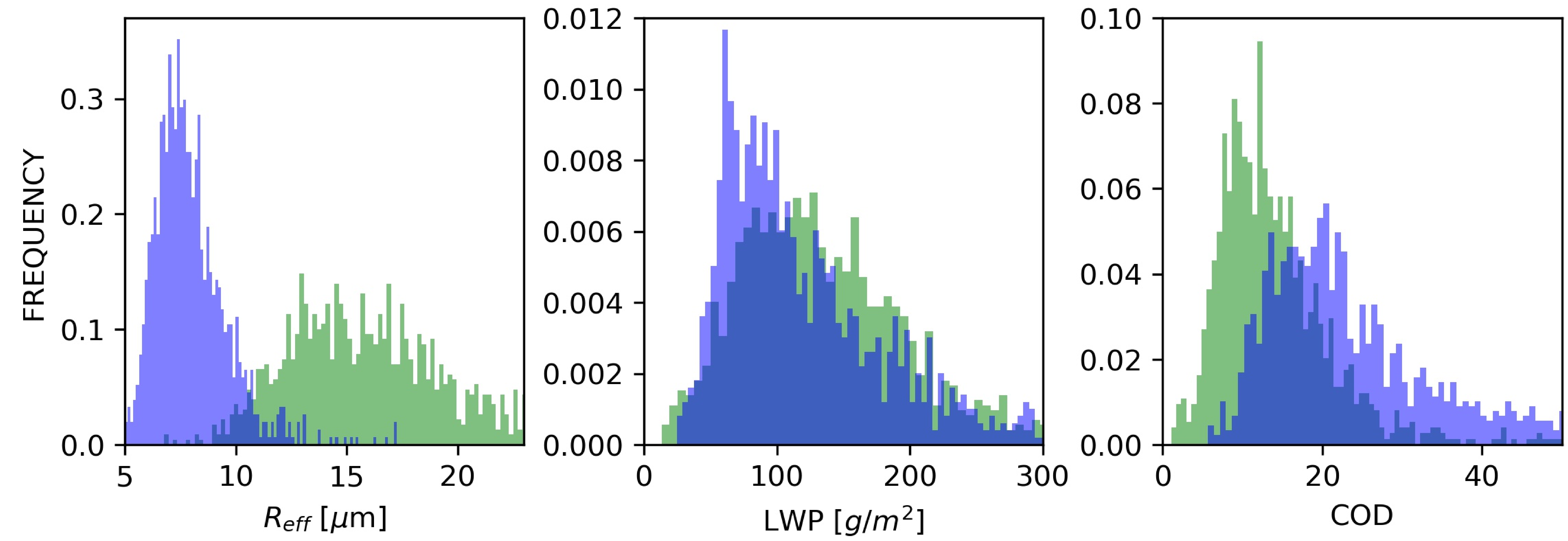
Figure 7. 


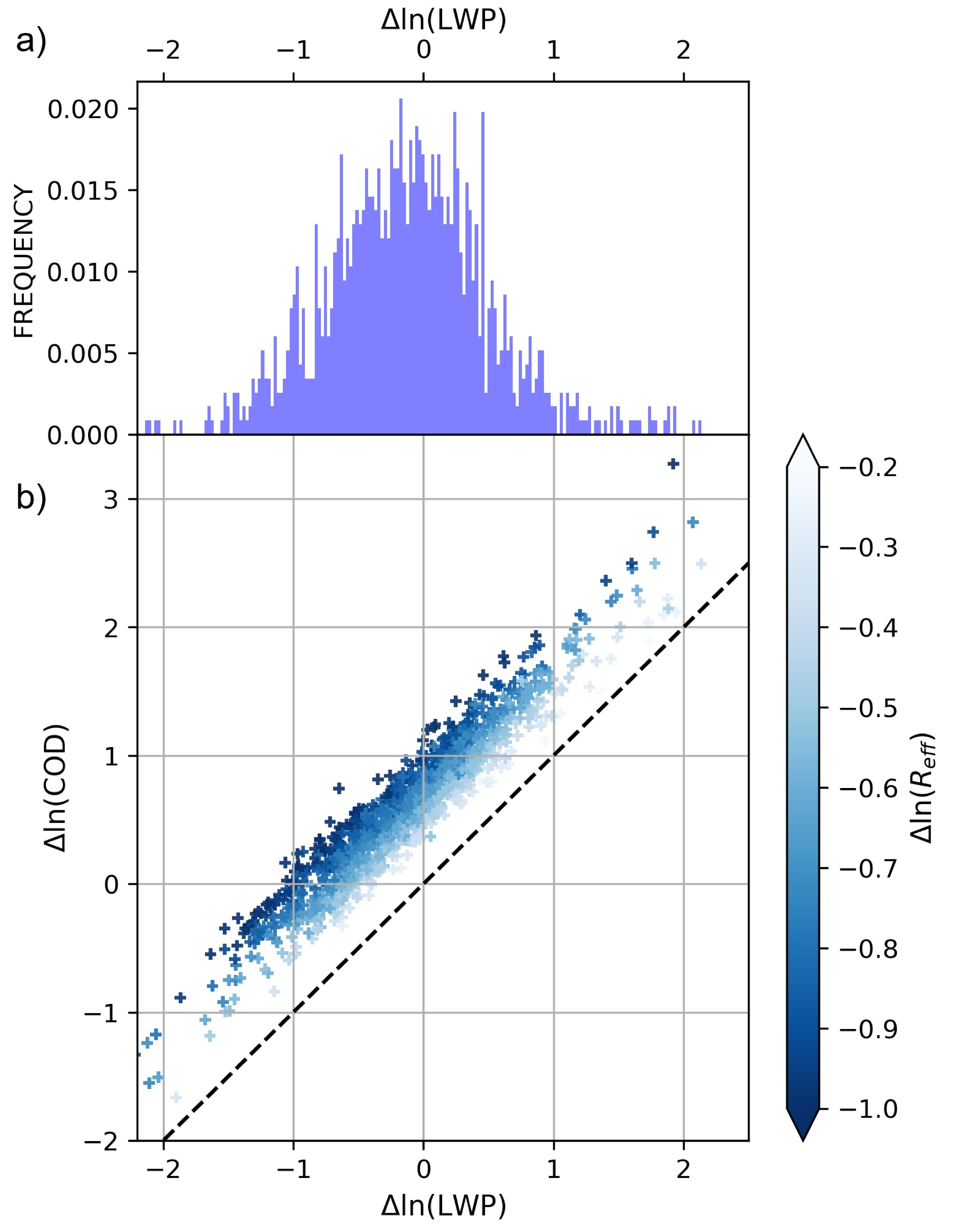


Figure 8. 
Figure 9. 

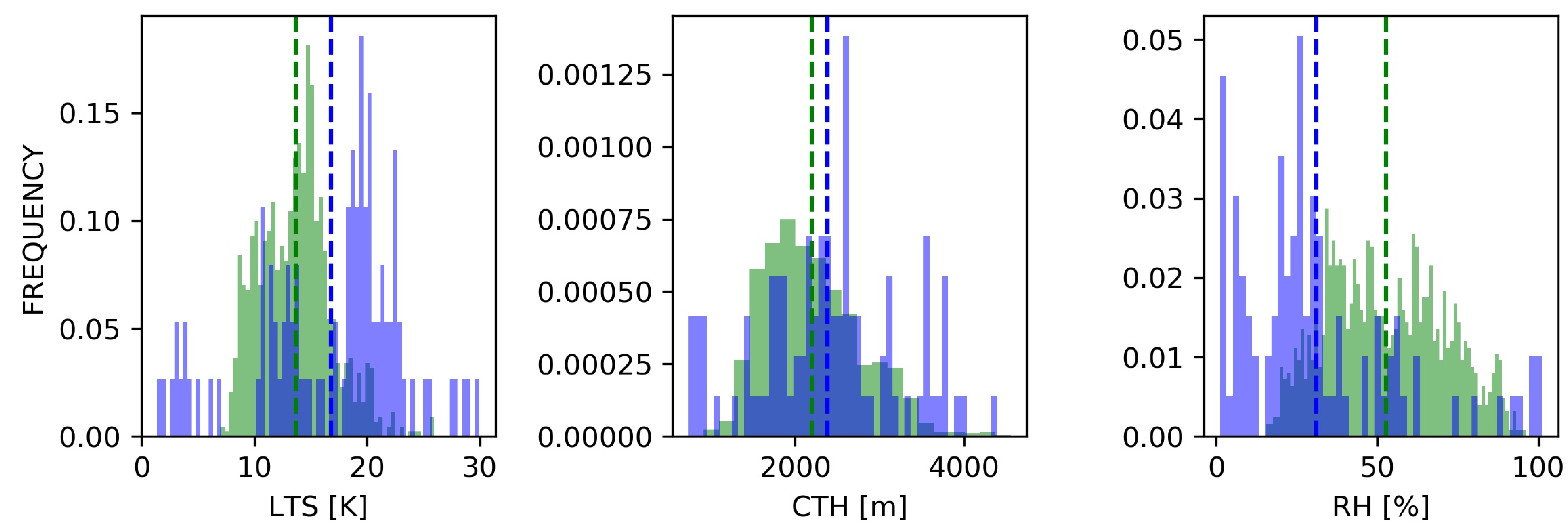